\title{
Experimental Study on the Seismic Behavior of RC Round Columns Strengthened by High Performance Ferrocement Laminates
}

\author{
Longmin JIANG, Wenjing LIU, Xiang YI \\ School of Civil Engineering,Hunan University of Technology \\ Zhuzhou, China \\ e-mail: 527943658@qq.com,1322941546@qq.com,1049877158@qq.com
}

\begin{abstract}
Based on the experimental study of four RC full-size round columns under constant axial loading and lateral cyclic loading, the effectiveness of strengthening the $\mathrm{RC}$ round columns using the high performance ferrocement laminates (HPFL) for improving their seismic behavior has been examined. And with the powerful constraint function to the concrete and anchoring effect to longitudinal steel bar of mesh established in the way of dense transverse steel bar of mesh in the dangerous range of concrete, not only the seismic loadbearing capacity of the strengthened columns increases to varying levels, but also the seismic ductility improves to a greater degree and the total energy dissipation ability improves to a higher extent. In detail,with once-loading strengthening column, the seismic load-bearing capacity increased obviously due to the unobvious phenomenon of strain lag of HPFL to primary column concrete; for the twice-loading strengthening column as well as twice-loading strengthening column with seismic damage, although the problem of strain lag of HPFLs to primary columns concrete is more prominent one by one , their seismic ductility has been improved increasingly in turn, and the latter's $P-\Delta$ envelopes curve with the downside rebounded, as a result of HPFLs' delayed acting and the increased capability of turning around of plastic hinges caused by the HPFLs' strong restriction mechanism working gradually. The HPFL can obviously improve the mode of longitudinal and transverse cracks for the strengthening round columns. Through the analysis of strain hysteresis performance of the columns' key points, the improvement reasons of seismic performance of the strengthened columns under different condition of strengthening and the degree of participating action in each loading stages of the HPFLs' bothway steel bar has been furtherly explored.
\end{abstract}

Keywords-high performance ferrocement laminates (HPFL); seismic strengthening; twice-loading strengthening; load-bearing capacity; ductility

\section{INTRODUCTION}

In our country, 70 percent of the terrain is in earthquake area; and most of the old houses and bridges are without earthquake fortification, therefore, they are urgently to be strengthened.

Many post-earthquake survey results show that one of the main damage comes from RC columns destruction. Also, some research findings and engineering practices indicate that the load-bearing capacity and ductility of the column can be greatly improved by external constraint from the strengthened part of the RC column(plastic hinges, that is within $1.5 h$ to the column bottom, $h$ is section height or diameter of the original columns ) or the whole body of the column strengthened by pasting steel plate, enlarging section, winding galvanized wire or pasting fibrous materials and other winding forms ${ }^{[1 \sim 6]}$. The method of strengthening $\mathrm{RC}$ structures using HPFL ${ }^{[7]}$ obtained by the improving age-old ferrocement has a lot of comprehensive features, such as remarkable reinforcement effect, easy to construct, low cost, fire proofing and high temperature resistance, lasting long and anti-aging, fine consistency and harmony with the original component concrete, inconspicuous section enlargement and good environmental protection; at present, rather systematic research results ${ }^{[8 \sim 14]}$ has been achieved in this area and popularized and used well at home ${ }^{[15 \sim 17]}$. In the present concrete structure, a lot of columns with square sections or round sections are used in tall buildings and bridges widely. In Reference [9], the seismic performance of RC square column strengthened by HPFL has been studied, therefore, the research of seismic property of $\mathrm{RC}$ round column strengthened by HPFL is also of equal important engineering significance, which can realize the purpose of supplement and perfecting the existing research results.

\section{TEST STUDY}

\section{A. Basic Test Specimens and Test Scheme}

The same as Reference [9], the reversed $\mathrm{T}$ shape specimens are used to simulate the half column below the inflection point of the frame column. And 4 reversed T shape specimens are made in the test, of which the diameter of section of each cantilever column is $375 \mathrm{~mm}$, the column height is $1500 \mathrm{~mm}$ from top of transverse beam to the horizontal force loading point, the longitudinal bar of the primary column is HRB335 deformed steel bar (the actual yield strength is $f_{\mathrm{y}}=358 \mathrm{MPa}$ ), the column stirrup is HPB 235 round steel bar (the actual yield strength is $f_{\mathrm{y}}=281 \mathrm{MPa}$ ). The bottom of each specimen is designed to as $2000 \mathrm{~mm} \times 700 \mathrm{~mm} \times 420 \mathrm{~mm}$ rigid transverse beam. For the detailed design of the specimen, see Fig.1. The concrete strength grade is C35. In order to test the actual strength of the concrete in good time, each test specimen has two sets of test cubes curing under the same condition, and the measured values are in Table 1. 

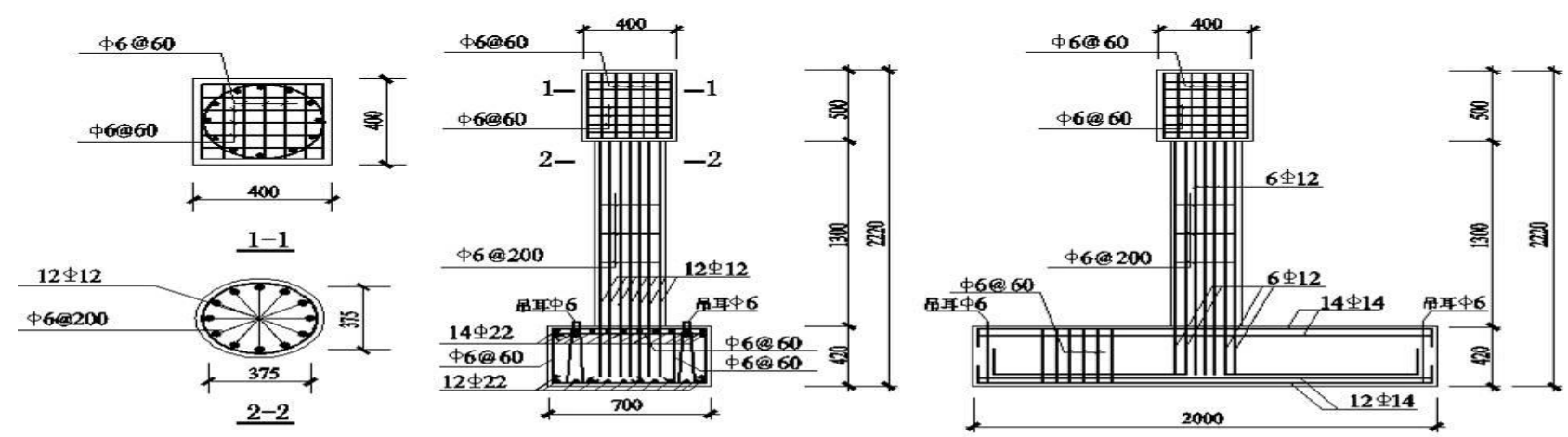

Figure 1. The details of basic specimens.

The axial compression ratios of four cantilever columns determined according to the actually imposed axial load and to the actual concrete compression strength and to the section size of the original column are equal $n=0.42$. Of which, $R-1$ is the unstrengthened comparison column; R-2 is the onceloading strengthened column, that is the test scheme "strengthening $\rightarrow$ imposing axial force $\rightarrow$ impose low cycle horizontal load" to simulate the seismic strengthening of the column which can completely unload the axial load; R-3 is the twice-loading strengthened column without unloading axial load, that is using the test scheme "imposing axial force $\rightarrow$ strengthening $\rightarrow$ impose low cycle horizontal load" to simulate the seismic strengthening of the column under the condition of without unloading or incompletely unloading the axial load; R-4 is the twice-loading strengthened column without unloading axial load and pushed the column to bottom longitudinal bars yielding, that is using the test scheme "imposing axial force $\rightarrow$ impose low cycle horizontal load to the yielding of the original column's longitudinal bars as the test points $\left(1^{\prime}\right)$ and $\left(7^{\prime}\right)$ in fig. $4^{\prime \prime}$ to simulate the seismic strengthening of the damaged and repairable or reinforced column under the condition of without unloading or partially unloading the axial load.

To avoid the bad failure mode caused by longitudinal reinforcements of the HPFL contradicting directly to the top surface of transverse beam when the column top reach large horizontal displacement, there is a $15 \mathrm{~mm}$ space between bottom end of HPFL and top surface of transverse beam. Strengthen the whole area of R-2,R-3,R-4 and keep the space of horizontal reinforcements in the potential plastic hinge area( $1.5 h$ to the column bottom ) to be half of not plastic hinge area in the HPFL to increase the confining effect of the concrete and the anchoring function of the longitudinal reinforcement in this part. See Table 1 for the major parameters of column test.

\section{B. Strengthening Method and Process}

The materials and structure of HPFL are the same as that in Reference [9]. Cold-rolled ribbed reinforcement with diameter 46.45 , actual monofilament yield tensile strength and ultimate tensile strength fy $=551.2 \mathrm{MPa}$ and $\mathrm{fu}$ $=627.7 \mathrm{MPa}$, reinforcement gridding size $50 \mathrm{~mm} \times 50 \mathrm{~mm}($ not plastic hinge area) and $50 \mathrm{~mm} \times 25 \mathrm{~mm}$ (plastic hinge area), is used for the wild phase of HPFL, High-performance composite mortar mating with efficient inorganic interface adhesion agent[8] is used for base phase of HPFL.

TABLE I. Main Testing Results Of All Specimens

\begin{tabular}{cccccc}
\hline & Crack & \multicolumn{2}{c}{$\begin{array}{c}\text { Ultimate flecural } \\
\text { capability }\end{array}$} & \multicolumn{2}{c}{$\begin{array}{c}\text { Displacement } \\
\text { ductility factor } \boldsymbol{\mu}_{\boldsymbol{\Delta}}\end{array}$} \\
\cline { 3 - 6 } No. & $\begin{array}{c}\text { load } \\
\text { /kN }\end{array}$ & $\begin{array}{c}\text { Test } \\
\text { value } \\
\text { /kN.m }\end{array}$ & $\begin{array}{c}\text { Increase } \\
\text { rate/ } \%\end{array}$ & $\begin{array}{c}\text { Test } \\
\text { value }\end{array}$ & $\begin{array}{c}\text { Increase } \\
\text { rate } \\
/ \%\end{array}$ \\
\hline & & & & & \\
R-1 & 111.05 & 230.23 & - & 3.17 & - \\
R-2 & 118.25 & 277.76 & 20.64 & 6.95 & 119.24 \\
R-3 & 107.75 & 239.31 & 3.94 & 7.84 & 147.32 \\
R-4 & 110.37 & 242.81 & 5.46 & 9.44 & 197.79 \\
\hline
\end{tabular}

TABLE II. MAJOR PARAMETERS OF THE TeSt SPECIMENS

\begin{tabular}{ccccc}
\hline $\begin{array}{c}\text { Column } \\
\text { NO. }\end{array}$ & $\begin{array}{c}\text { Steel } \\
\text { bar } \\
\text { ratio }(\%)\end{array}$ & $\begin{array}{c}\text { Concrete } \\
\text { strength } \\
\boldsymbol{f}_{\text {cu }} \mathbf{M P a}\end{array}$ & $\begin{array}{c}\text { Axial } \\
\text { compression } \\
\text { ration }\end{array}$ & Strengthening condition \\
\hline $\mathrm{R}-1$ & 1.228 & 35.95 & 0.42 & No strengthening \\
$\mathrm{R}-2$ & 1.228 & 36.24 & 0.42 & Unload axial load \\
$\mathrm{R}-3$ & 1.228 & 37.82 & 0.42 & No unload axial load \\
R-4 & 1.228 & 36.66 & 0.42 & $\begin{array}{c}\text { Nounload axial load and has } \\
\text { seismic damage }\end{array}$ \\
\hline
\end{tabular}



Figure 2. Test set-up.

(1) First, for the area except $15 \mathrm{~mm}$ height to the column bottom, side dabbing, till the coarse aggregate comes out.

(2) Wash the rough surface of the column body with pressure water and at the same time brush the loose powder with steel wire brusher 
(3) After the specimen dries to deep gray, brush the concrete rough surface with a little soupy interface adhesion agent.

(4) Lay the cystosepiment with $15 \mathrm{~mm}$ thickness on the top surface of transverse beam and close to the original column. Bind and locate the longitudinal and horizontal reinforcement precisely as the size $50 \mathrm{~mm} \times 25 \mathrm{~mm}$ (upward $500 \mathrm{~mm}$ height from the cystosepiment top surface) and $50 \mathrm{~mm} \times 50 \mathrm{~mm}$ (the upper area). The longitudinal reinforcement is placed inner layer and the horizontal reinforcement is placed out layer with the overlapping length $100 \mathrm{~mm}$. Through electro welding the cross point and overlapping position makes it become the hoop cage close to the original column.

(5) Paint the composite mortar mixed mechanically to the original column side twice, the first coat should be rubbed violently to ensure the mortar densely combined with the concrete and bar-mat reinforcement. The thickness of HPFL shall be about $25 \mathrm{~mm}$.

(6) Cure each specimen under the normal temperature and wet condition for at least $28 \mathrm{~d}$. The above reinforcing construct method and process can be applied to the site operation completely.

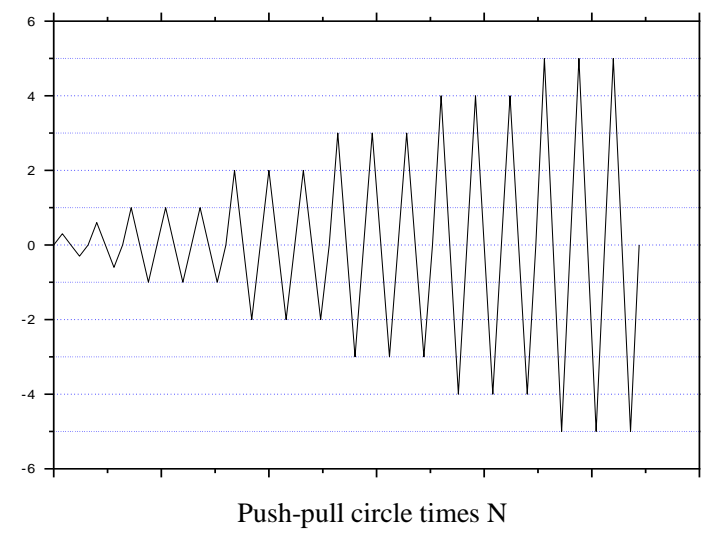

Figure 3. Loading history.

\section{Test Set-Up, Loading History and Test Content}

The test set-up and loading history are the same as Reference [9], that is to use loading system with the numerical control and power-driven hydraulic servo pushpull actuator and loading history by controlling displacement changing ${ }^{[18]}$, see fig.2 and fig.3. For the twice-loading strengthened column R-2 and R-3 without unloading axial load, because of the early strength agent and well curing condition, the composite mortar of HPFL has reached the design strength in $3 \sim 4 \mathrm{~d}$, and during this period, use the stabilivolt operation of hydraulic system to keep the constancy of axial load.

Test content includes:

(1) P- $\Delta$ hysteretic curve of each specimen( $\mathrm{P}$ is the horizontal push-pull force effecting in the column top, and $\Delta$ is the horizontal displacement of effecting point of force $\mathrm{P})$. $\mathrm{P}$ is recorded by the loading pressure box on the actuator and the both-way force sensor installed between the actuator and column head with $850 \mathrm{kN}$ range, $\Delta$ is measured by the displacement sensor in the actuator. Meanwhile, the measured value of $\mathrm{P}$ and $\Delta$ is collected, stored automatically by the corresponding computer program and the P- $\Delta$ curve segment under the each loading step length shall be drawn synchronously.

(2) The strain value $\varepsilon$ of the test points of each structural layer in the plastic hinge area under each loading step length. The detailed arrangement of each structure layer test points is shown in fig. 4. The numbers in and out the bracket are respectively the vertical and horizontal strain gauge number of test point. The stain value of each loading step is collected by two DH 3816 signal tester and computer.

(3)Crack observation. Monitor and observe the occurrence time, model and development of the crack under each loading step.

(4) Corner measurement of the upper end of column. Use the inclinometer fixed in the intersection point of $\mathrm{P}$ line of force and column axes to measure the corner of the upper end column directly.

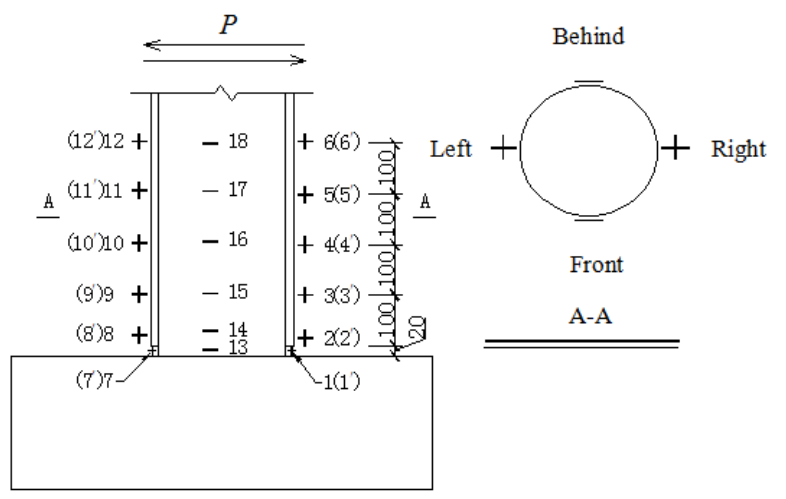

Figure 4. Layout diagram of test strain points.

Table 2 is the main test result of each specimen and the detailed contrast information. In the table, the displacement ductility factor $\mu_{\Delta}$ is calculated as the formula in Reference [9]. And fig. 4 is the $P$ - $\Delta$ hysteretic curve of each specimen.

\section{TESt RESUlts AND ANALYSIS}

\section{A. Main Failure Characteristics and Analysis}

Four specimens show large eccentric compression failure, respectively. Fig.6 is the failure mode of each column and the failure characteristics are summarized as follows:

(1) Unreinforced contrast column R-1: before the yielding of tension longitudinal bar at test points $\left(1^{\prime}\right)$ or $\left(7^{\prime}\right)$ in the lower part of the column, P- $\Delta$ hysteretic curve is basically in linear variation. When the side displacement reaches $8 \mathrm{~mm}$, there are 6 visible horizontal cracks (tension crack) next to the root of the bottom and the upper area, which are thinner and thinner with $10 \mathrm{~cm} 30 \mathrm{~cm}$ crack space. When the side displacement reaches $12 \mathrm{~mm}$, test point ( $1^{\prime}$ ) longitudinal bar is tensed and yield. 


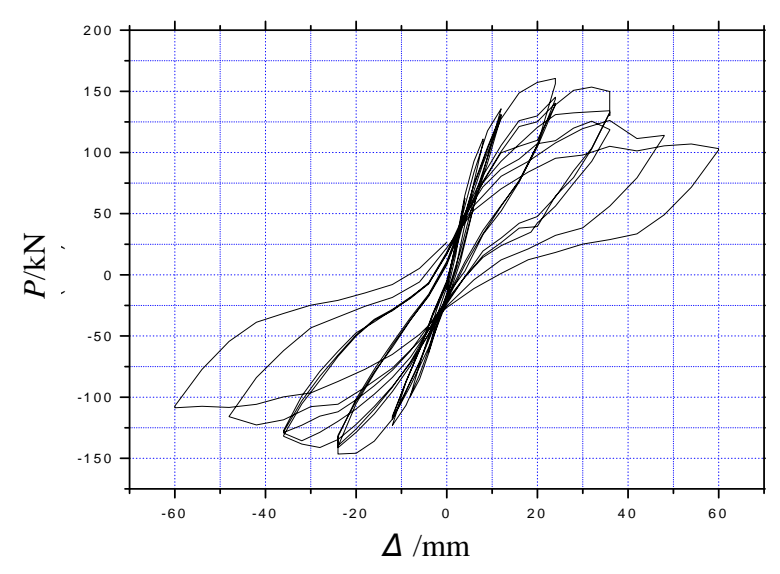

(a) R-1 $(n=0.42)$

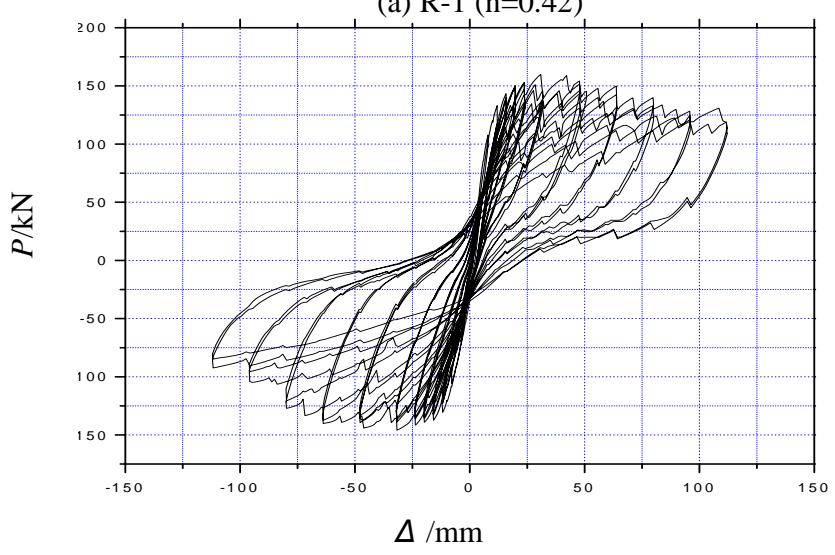

(c) R-3 (n=0.42)

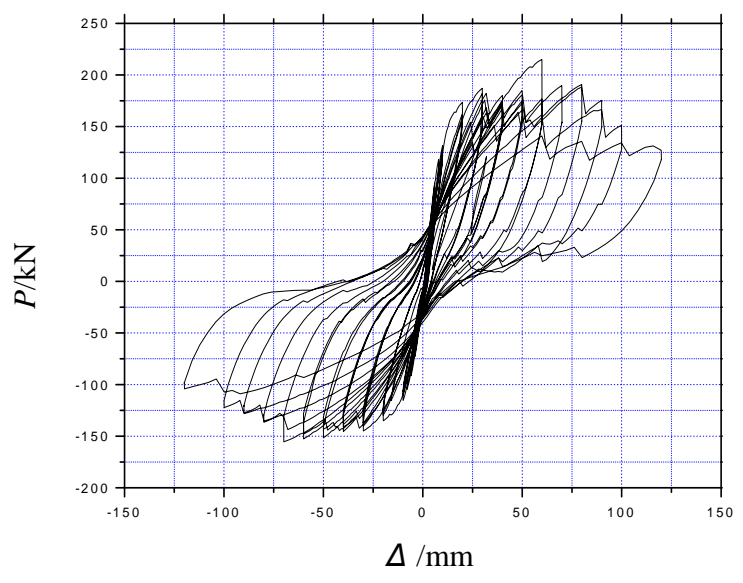

(b) $\mathrm{R}-2(\mathrm{n}=0.42)$

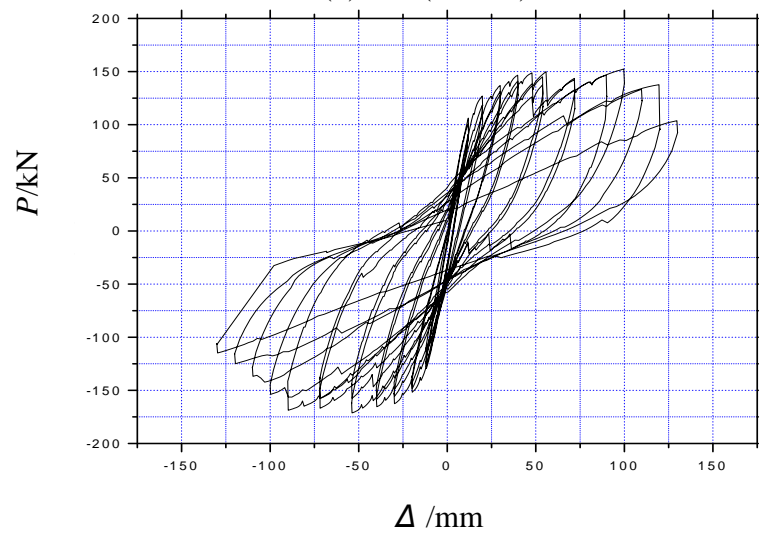

(d) R-4 ( $n=0.42)$

Figure 5. Hysteretic Loops of P- $\Delta$ response.

\section{B. Main Testing Results}

(1) Other columns are the same with $\Delta y=12 \mathrm{~mm}$ ), and the longitudinal bar strain increases fast with horizontal cracks widening and extending to two sides and few new cracks. As the horizontal side displacement increases continually, each crack with different extension to two sides becomes curved scissors diagonal crack with certain gradient. When close to failure, curved scissors diagonal cracks caused by bothway load do not intersect, and the hoop reinforcement at two sides missed the yield strain. When the plastic hinge area is pressed, the concrete swelled rapidly and fell off in bulk; then the component reaches the maximum load capability. Thereafter, the tension strain of the hoop reinforcement at the lower part of the column develops fast and the load capability falls rapidly, and the longitudinal bar bloats to lantern shape as fig.6 (a). At last, because the core concrete is pulverized further, the column body falls down and the test ends.

(2) Once stressed and reinforced round column R-2: before the yielding and tension of the original column longitudinal bar of test point (1') in the HPFL lower part space, P- $\Delta$ hysteretic curve is basically in linear variation. When the side displacement reaches $8 \mathrm{~mm}$, the horizontal cracks appear in this space and junction between HPFL horizontal net reinforcement fine meshed area and the upper normal area. After (1') longitudinal bar tensions and yields, the horizontal cracks increase upward, grow horizontally and dense in space, of which the cracks extend to two side of the column, the extension length becomes shorter and shorter from bottom to top along the column. What is different to the contrast column is the tensioned horizontal cracks do not become slant curved scissors cracks only the horizontal fracture caused by bothway load which meet at two sides without shear failure, which proves that the reinforced columns are improved clearly than the contrast columns. When the sideway horizontal displacement reaches $40 \mathrm{~mm}$, the stressed concrete in the plastic hinge area deforms and increase horizontally and the longitudinal cracks appear from HPFL bottom, HPFL horizontal stain increases rapidly and it reaches the maximum bearing capacity when there are some fragment concrete popupping form the space of the column bottom. From fig.5(b), we can see there exists uprush of bearing capability, which proves that once stress reinforced column greatly improved the bearing capability in HPFL which sets to work in the middle period of closing to load. Hereafter, the concrete in the stress area of the column bottom swells rapidly, longitudinal cracks develop to conical 


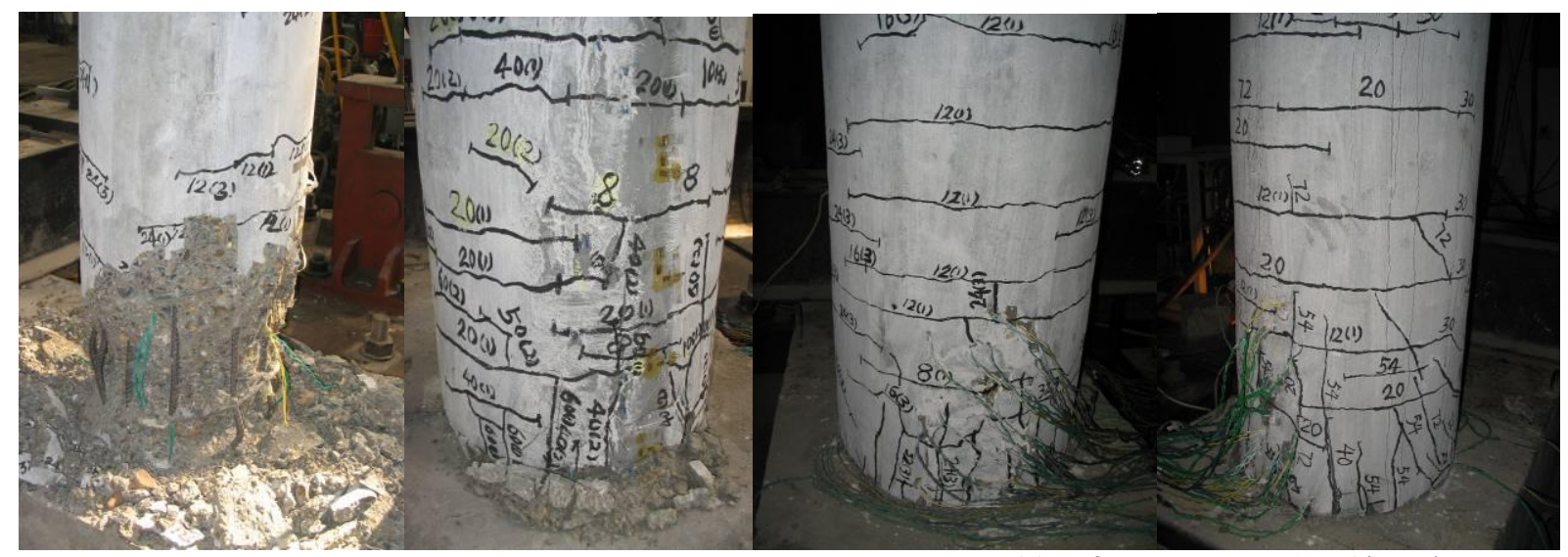

(a) R-1

(b) R-2

(c) R-3

(d) R-4

Figure 6. Failure mode of test columns.

lip shape with the extension length reaching to the whole range of the plastic hinge area, and the horizontal net reinforcement tension strain increase rapidly till broken with the component's bearing capability decreasing constantly. When knocking off the HPFL mortar of the column bottom after the test, four horizontal net reinforcement at the column bottom are found broken, and the inner crashed concrete can be scrabbled easily without block concrete dropping, see fig.6(b).

(3) the twice load-carrying reinforced column without disburdening axial force R-3: the failure process and mode are similar to that of R-2, but because R-3 is the reinforced column without disburdening axial force, its failure characteristics are as follows: (1) there is strain hysteresis phenomenon in R-3 HPFL, because there is some horizontal tension strain in R-2 and zero in R-3 HPFL before exerting horizontal load; (2) in the rising phase of hysteretic curve, load bearing capacity does not increase suddenly and HPFL does not work clearly; (3) when the side displacement reaches $20 \mathrm{~mm}$, there is a $15 \mathrm{~cm}$ one-way shear diagonal crack in both sides parallel to the horizontal force, but the crack does not extend forward, which proves that shear-stress failure effect similar to R-1 is controlled by HPFL; (4) when the component reaches the displacement corresponding to peak load, longitudinal cracks appear from the bottom of the stressed side HPFL, which further improves that HPFL strain hysteresis phenomenon of twice stressed reinforcement column is very obvious; (5)the distribution of horizontal cracks of R-3 ranges the whole column, and that of R-2 ranges the lower part of the column, which because the plastic hinge area extends caused by the strong function of restraint of HPFL suffering strain hysteretic when the former concrete has rather huge lateral deformation, therefore, the area of stress redistribution is widened. When knocking off the ripped HPFL screed in the lower part of the column after the test, there is no snapped horizontal net reinforcement, but the crushed area of concrete is taller than the original column. The final failure is still caused by the crushed concrete in the stressed area as fig. 6(c).

(4) Twice stress reinforced round column without discharge axial force and pushed to yieldingR-4: in the process of uploading the test point (1') before the yielding of longitudinal bar, R-4 and R-1 have the same manifestation. After unloading to the equilibrium position and being reinforced, and uploading until the yielding moves $\Delta y$, there are 7 horizontal cracks with wider and wider space and smaller and smaller length on the upper column of the horizontal net bar thickened area. When uploading to $30 \mathrm{~mm}$ side movement, there are several short and thin longitudinal cracks from the bottom of the HPFL. What is special is that there are unidirectional shear diagonal cracks on both sides with the same horizontal forces, such as fig. 6(d). With the increase of the column side movement, the quantity and length of the longitudinal and unidirectional shear diagonal cracks increase until the side movement reaches $72 \mathrm{~mm}$ (about 6 times of yielding movement), the unidirectional cracks stop developing, but the longitudinal cracks in the stressed area continue extending and increasing. It proves that during the uploading period, the damage effect at the column bottom is obvious, which may be caused by the HPFL of R-4 later than that of R-3 and makes the damage tendency same as comparison column. If there is no obvious cross diagonal crack but unidirectional diagonal cracks, it may be caused by the installation error of test specimen and the dissymmetry of forward and reverse uploading. In the later uploading process, the stressed concrete swells rapidly and made the longitudinal cracks longer than R-2 and R-3, which is the true manifestation of HPFL's delay operation and makes the declining bearing capacity rise again, such as 5(d). The decline of bearing capacity still comes from the oversized plastic deformation of tension longitudinal bar and the crushing of concrete in the stressed area. All the horizontal cracks are distributed in the range of $2 / 3$ column. The state after ending the test is the same as that of $\mathrm{R}-3$ except that two horizontal net bars are snapped in the middle part of the plastic hinge area.

\section{Skeleton Curve and Bearing Capacity, Ductility Improvement Mechanism Analysis}

Fig. 7 is the skeleton curve of each cantilever post, it is the envelope curve connected by the primary periodic peak 
point of each uploading, and it reflects the whole uploading process and ductility characteristics.

(1) Flexural strength and its improvement mechanism analysis the mean value of forward and reverse maximum bearing capacity as the maximum bearing capacity. From table 2, it is known that the improvement of flexural capacity of once stressed reinforced column R-2 is more obvious than that of R-3 and R-4.

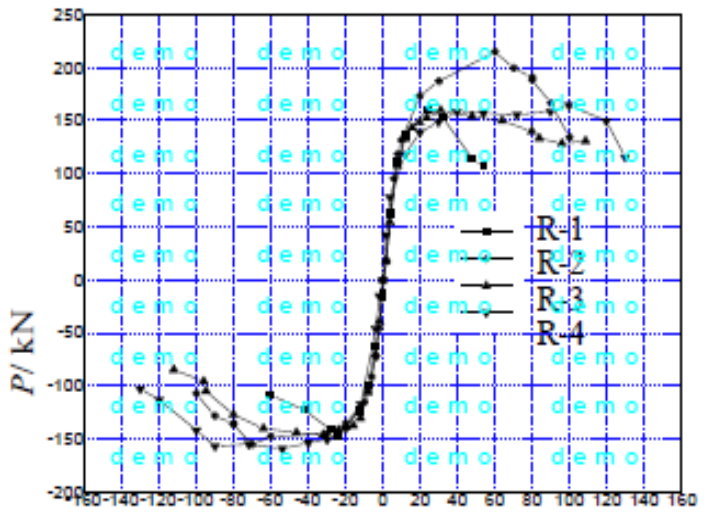

$\Delta / \mathrm{mm}$

Figure 7. Envelopes Curves.

Similar to seismic hardening square column, HPFL longitudinal net bar cannot resist the bend pull and pressure force of the column root directly, but the bar-mat reinforcement formed with horizontal net bar exerts more uniform and effective restraint in the plastic hinge area, the dangerous area of column concrete, and improves the stress state of concrete. Compared with square column, such restraint function of round column is more effective. The increase rate of bearing capacity of R-2 is over $20 \%$, this is because the HPFL strong restraint function of horizontal deformation basically synchronized with the original column concrete improves the concrete's compressive strength and peak value stress. For the second stressed reinforced round column R-3 and R-4, since the HPFL begin to work until the stressed concrete to be crushed, though, in some way, it restrains the development of stressed concrete small cracks and makes the declining bearing capacity rise in some way, but it is not obvious.

(2) Ductility and its improvement mechanism analysis From the test result in table 2, no matter it is discharge axial force reinforcement or without discharge axial force reinforcement, the reinforcement methods of enclosing and knotting reinforcing mesh composite mortar film in the column side face and thickening the horizontal net bar in the plastic hinge area of the column have the same effect in improving the ductility of the round column. R-2 reinforced by discharge axial force has the same restriction mechanism as that stated in reference [9]. For R-3 reinforced by without discharge axial force, although the restriction function of HPFL in the second phase is delayed in some way, in the process of plastic hinge running, because of the rapid development of circle tension strain.

\section{Stain Hysteretic Behavior Analysis of the Original Rebar and Back-Up Coat Net Bar}

In this part, the author tries to analyze the stain hysteretic behavior of some key part of each column to realize exploration on the judgment of the above damage modes, the improvement reason of anti-seismic performance after reinforcing, the effect of reinforcement under different stress condition, the degree of bothway net bar involving in operation and etc.

In fig. 8 , the ordinate "+" is tension stain and "-." is stress stain. Fig 8(a) is the hysteretic relation curve between stirrup stain and column side movement stain of the test point 15 in non strengthened column R-1. When the column reaches the maximum bearing capacity(the corresponding column side movement is $24 \mathrm{~mm}$ ), the stirrup is not yielded(the yielding stain is $1120 \mu \varepsilon$ ), proving that is non shear failure mode. Fig. 8 (b) is the hysteretic relation curve between the original column longitudinal bar stain and column side movement of test point (1') in the column root. When the column reaches the maximum bearing capacity, the longitudinal bar of test point (1') has reached $2340 \mu \varepsilon$ (the yielding stain is $1670 \mu \varepsilon$ ), and the later stain increases at full speed, which further proves the final failure mode is big side stress bending failure.

Fig $8(\mathrm{c})$ is the hysteretic relation curve between longitudinal net bar stain and column side movement stain of the test point 16 in once stressed strengthened column R-2. Fig $8(d)$ is the relation curve between longitudinal net bar stain and column side movement stain of the test point 4 of the same height in right side column. From these two figures, it is known that in the middle and later periods of uploading, the stain of test point 4 develops faster than that of test point 16 , which proves that the stain of longitudinal net bar is caused mainly by the longitudinal deformation of the stressed concrete restricted by the curved deformation of the column. The final failure mode is the big side stress bending failure of better ductility in contrast column R-1.

Fig.8(e) and fig.8(f) are respectively the hysteretic relation curve between the column side movement and the stain of the original column longitudinal bar of test point (1') and the stain of longitudinal net bar of test point (2') in the once stressed strengthened column R-2. From the figures, it is known that the tension strain of the longitudinal bar test point (1') which suffers the maximum tension stress develops very fast, which reaches about $8000 \mu \varepsilon$ when the side movement is only $20 \sim 30 \mathrm{~mm}$, while the longitudinal net bar stain of test point (2') which is close to (1') increases from fast to slowly because of the development of the horizontal cracks of the column root gap. Even so, it also can be seen that the longitudinal net bar helps the stressed concrete bear some pressure stress because of the anchoring function of the horizontal net bar. 


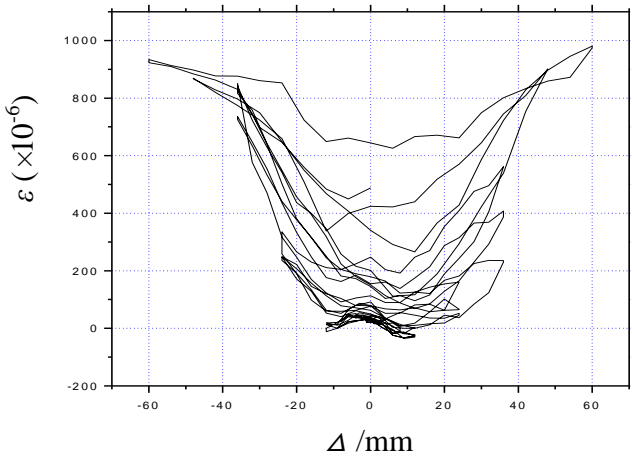

(a) Hooping of R-1 Original Columns(Test Point 15)

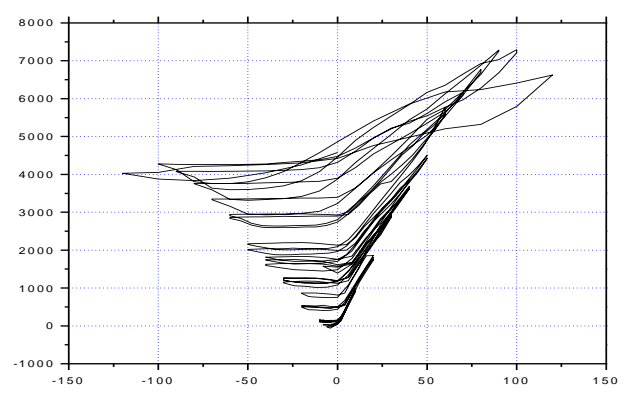

(c) Net Bar of R-2 HPFL(Test Point 16)

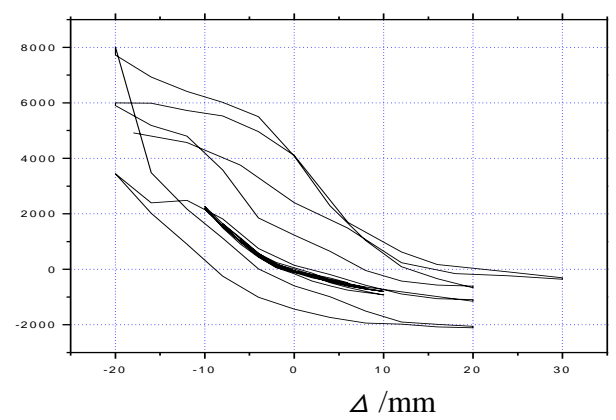

(e) Bar of R-2 Original Columns(Test Point 1')

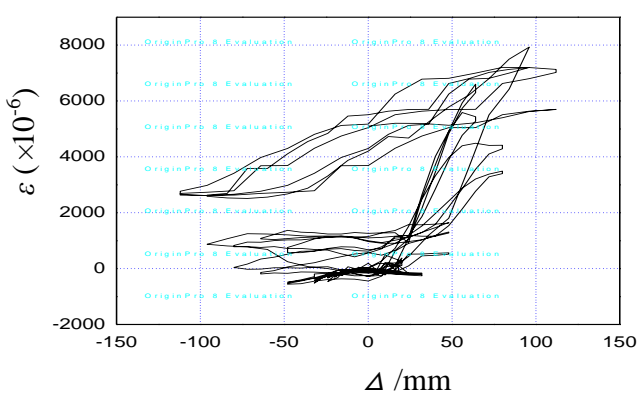

(g) Net Bar of R-3 HPFL(Test Point 4)

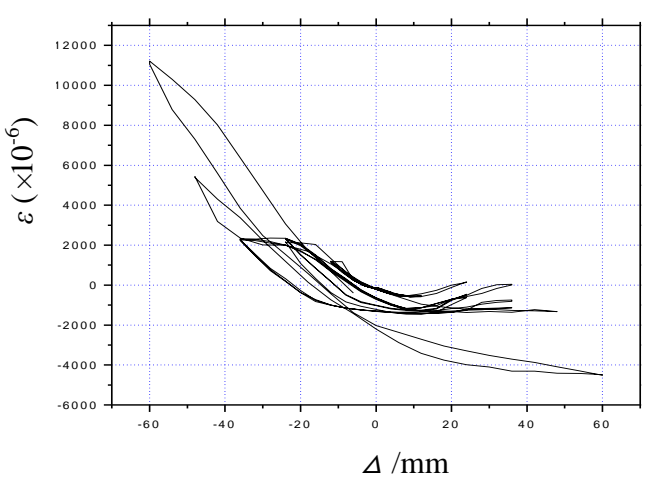

(b) Bar of R-1 Original Columns(Test Point 1')

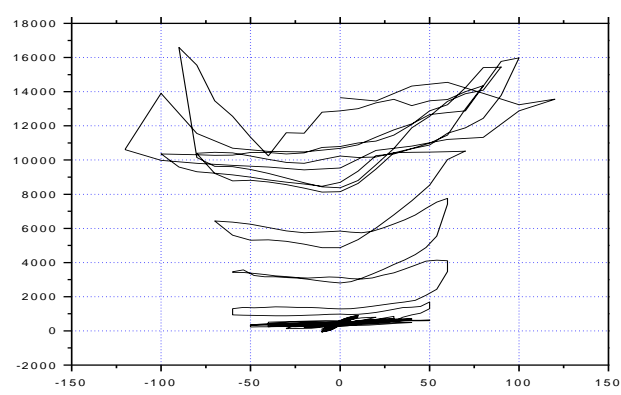

(d) Net Bar of R-2 HPFL(Test Point 4)

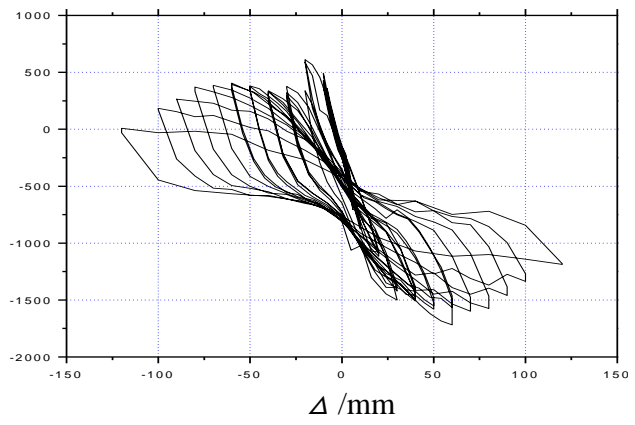

(f) Net Bar of R-2 HPFL(Test Point 2')

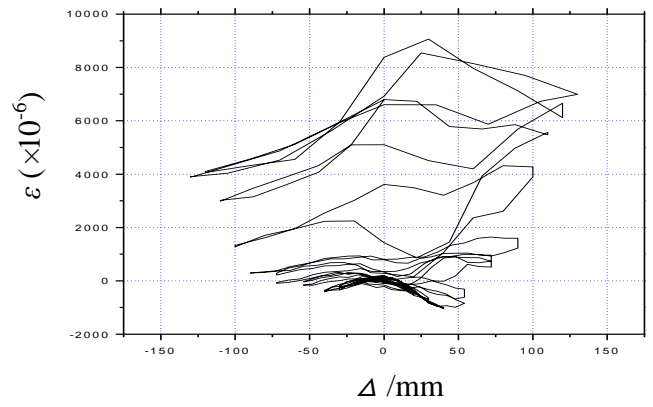

(h) Net Bar of R-4 HPFL(Test Point 4)

Figure 8. Hysteretic loops of strain of the original columns bar and the HPFL net bar.

Fig. $8(\mathrm{~g})$ is the hysteretic relation curve between the stain of test point 4 horizontal net bar and the column side movement of twice load-carrying reinforced column without disburdening axial force R-3; Fig. 8(h) is the hysteretic relation curve between the stain of test point 4 horizontal net bar and the column side movement of twice load-carrying 
reinforced column without disburdening axial force and with earthquake damage R-4; from the comparison between $8(\mathrm{~d})$, $8(\mathrm{~g})$ and $8(\mathrm{~h})$, we can know that under three different stress condition, the development of horizontal net bar stain at the same position of the reinforced column is obviously unsynchronized as in table 3 . Under the same side-movement condition, R-3 falls behind R-2 and R-4 behind R-3. When each column reaches its peak value load Pmax, R-3 obviously falls behind R-2 while R-4 has no response. The rapid development of the later stain of R-4 reinforced layer makes the declined bearing capacity rise again. Because of the serious development of microcrack of the concrete, the rising extent of the bearing capacity is small (the second peak point is about $4 \%$ higher than Pmax of the first peak point), but the stain discrepancy of the horizontal net bar of test point 4 with the corresponding peak point is $4000 \mu \varepsilon$, which makes the ductility improves greatly, see 5(d) and fig. 7 for the details. When falling to $15 \%$ Pmax, from the horizontal net bar stain of the test point 4 of each column, we can see that R-2 reinforced layer works quite early with the total stain too large; the later rapid development of R-3 and R-4 makes the rollback of column bearing capacity slow and greatly raises the column ductility, and this characteristic of $\mathrm{R}-4$ is especiallobvious.

TABLE III. Strain CONTRAST OF TRANSVERSE Net Bars of TeSt POINTS 4 OF THE STRENGTHENING COLUMNS' HPFL

\begin{tabular}{|c|c|c|c|c|c|c|}
\hline \multirow[b]{2}{*}{ TestNo. } & \multicolumn{2}{|c|}{ Whenreaches $4 \triangle_{\mathrm{y}}$} & \multicolumn{2}{|c|}{ When reaches $P_{\text {mix }}$} & \multicolumn{2}{|c|}{$\begin{array}{l}\text { Droptp } \\
85 \% P_{\max }\end{array}$} \\
\hline & $\begin{array}{c}\text { Side } \\
\text { mov } \\
\text { emen } \\
\mathrm{t} \\
/ \mathrm{mm}\end{array}$ & $\begin{array}{l}\text { stain } \\
/ \mu \varepsilon\end{array}$ & $\begin{array}{l}\text { Side } \\
\text { movement } \\
\text { /mm }\end{array}$ & $\begin{array}{l}\text { stain } \\
/ \mu \varepsilon \varepsilon\end{array}$ & $\begin{array}{l}\text { Side } \\
\text { movement } \\
/ \mathrm{mm}\end{array}$ & $\begin{array}{l}\text { stain } \\
/ \mu \varepsilon\end{array}$ \\
\hline $\begin{array}{l}\text { R-2 } \\
\text { R-3 } \\
\text { R-4 }\end{array}$ & $\begin{array}{l}48 \\
48 \\
48\end{array}$ & $\begin{array}{l}1000 \\
560 \\
350\end{array}$ & $\begin{array}{c}60 \\
36 \\
100\end{array}$ & $\begin{array}{c}4000 \\
250 \\
0(\text { peak point } 1) \\
4000 \text { (peak } \\
\text { point2) }\end{array}$ & $\begin{array}{c}80 \\
82 \\
120\end{array}$ & $\begin{array}{l}11000 \\
4550 \\
6650\end{array}$ \\
\hline
\end{tabular}

\section{CONCLUSION}

(1) Using high-performance ferrocement laminates film to strengthen reinforced concrete column is an effective strengthening method for improving its anti-seismic property. The turning power of plastic hinge is increased because of the strong restraint function formed by thickening horizontal net bar in the dangerous area of column concrete, and then greatly improves the column ductility. At the same time, the thickened horizontal net bar at the column end forms anchoring function to the longitudinal net bar, and forces it to share the axial pull and pressure stress, which in a way improves the flexural capacity and also prevents the stripping and damage of the strengthening layer to a large degree.

(2) For once stressed reinforcing column with discharge axial force, the stain development of reinforced layer and the original column concrete is basically synchronized, which greatly improves the column anti-seismic capacity. For that more accordance with the engineering practice, twice stressed strengthening without discharge axial force and that with earthquake damage, the phenomenon of the strengthening layer stain delaying the concrete of the original column successively sharpens, and its playing roles successively delays, but the range of its ductility improvement increases successively, even making the declining P- $\Delta$ skeleton curve rise again and the recovery point load exceed the former point load.

(3) For twice stressed strengthening column, the horizontally distorted stressed concrete in the plastic hinge area makes the plastic hinge area develop after the stain hysteretic HPFL strong restriction function, that is the range of stress redistribution enlarges and the column stress is more uniform.

(4) The fiber composite mortar strengthened by bar-mat reinforcement can obviously improve the horizontal and longitudinal crack shape and distribution pattern of the reinforcing column.

(5) Through reasonably designing the ratio and form of reinforcement of the horizontal net bar in the plastic hinge area of the column ends can reach the expected anti-seismic strengthening effect.

(6) Anchoring the longitudinal net bar into the substrate, the frame joint, is a more effective compression-flexure member strengthening form, which will be the future study of the paper.

\section{REFERENCES}

[1] Wancheng G.Simsch. Flexural ductility of confined high strength concrete columns under cyclic loads[J]. China Civil Engineering Journal, 1995,28(5):55-61 (in Chinese)

[2] Nanni, A., Norris M S. FRP jacketd concrete under flexure and combined flexure-compression $[\mathrm{J}]$. Construction and Building Materials, 1995,9(5): 273-281

[3] ] Jose L, Ramirez. Ten concrete column repair methods[J] Construction and Building Materials, 1996,10(3):195-202

[4] ZHAO Tong, LIU Mingguo, XIE Jian, Investigation on application of continuous carbon fiber sheet to improve ductility of reinforced concrete columns[J]. Earthquake Engineering and Engineering Vibration, 2000, 20(4): 66-72(in Chinese)

[5] XIAO Jianzhuang. LONG Haiyan. SHI Xuefei . Study on seismic behavior of high-level axial compression concrete columns strengthened with FRP[J]. Journal of Tongji University(natural science), 2004, 32(8): 991-995 (in Chinese)

[6] ] Mohammad T K, Reza M. Seismic shear strengthening of R/C columns with ferrocement jacket[J]. Cement \& Concrete Composites, 2005, 27(3): 834-842

[7] JIANG Longmin, SHANG Shouping, HUANG Zhengyu. Fiber reinforced composite mortar and interfacial adhesive for strengthening of RC structures with ferrocement[J]. China Civil Engineering Journal, 2005, 38(5):41-47 (in Chinese)

[8] SHANG Shouping, JIANG Longmin, ZHANG Maoxin. Experimental investigation into the strengthening of eccentric compression RC column using composite mortar laminate reinforced with mesh reinforcement[J]. Journal of Building Structures, 2005,26(2):18-25 (in Chinese)

[9] SHANG Shouping, JIANG Longmin, ZHANG Maoxin. Study on seismic behavior of RC square columns strengthened using highperformance composite mortar reinforced with mesh reinforcements[J]. Journal of Building Structures, 2006,27(4):16-22 (in Chinese)

[10] JIANG Longnmin. SHANG Shouping. LIU Longhai. Experimental 
investigation and research on calculation method of load-carrying capacity for eccentrically compressed RC columns strengthened by high performance ferrocement laminates under twice loading[J]. Journal of Building Structures, 2011,32(4):72-79 (in Chinese)

[11] Jiang Longmin. Shang Shouping. Liu Fangcheng. Research on axially compressed behavior of RC strengthening round columns using high performance composite cement mortar reinforced with mesh reinforcements[J]. Jurnal of Hunan University of Technology, 2009,23(1):41-47 (in Chinese)

[12] SHANG Shouping. ZENG Linghong. DAI Rui. Experimental study on flexural behavior of reinforced concrete beams strengthened with ferrocement under secondary load[J]. Journal of Building Structures, 2005, 26(5): 74-80 (in Chinese)

[13] SHANG Shouping. ZENG Linghong. PENG Hui. Nonlinear analysis of reinforced concrete beam strengthened with ferrocement[J], Engineering Mechanics, 2005, 22(3):118-125 (in Chinese)

[14] ZENG Linghong. SHANG Shouping. WAN Jianping. Static and fatigue experimental study on reinforced concrete beams strengthened with high-performance ferrocement[J]. Journal of Building Structures, 2008, 29(1):23-26 (in Chinese)

[15] SHANG Shouping, JIANG Longmin, etc.Technical Specification for Strengthening Concrete Structures with grid rebar and mortar (China Association for Engineering onstruction Standardization), Beijing:China Planning Press,CECS 242:2008, (in Chinese)

[16] SHANG Shouping, JIANG Longmin, etc. Design and construction guidelines of strengthening concrete structures with high performance ferrocement laminates(M), Beijing:China Building Industry Press, 2008. (in Chinese)))

[17] SHANG Shouping. Practical seismic technology for rural residential buildings(M), Beijing:China Building Industry Press, 2009. (in Chinese)

[18] JBJ101-96. Specification of test methods for earthquake resistant building(S), Beijing:China Building Industry Press, 2008. (in Chinese). 